\title{
A AVALIAÇÃO DA CURCUMINA E ANÁlOGOS COMO POTENCIAIS INIBIDORES DA ENZIMA UREASE
}

\section{THE EVALUATION OF THE CURCUMIN AND ANALOGUES AS POTENTIAL INHIBITORS OF THE UREASE ENZYME}

\author{
Débora Pereira Araujo ${ }^{1^{*}}$ \& Emanuel Henrique da Silva ${ }^{2}$ \\ ${ }^{12}$ Departamento de Ciências Naturais, Centro Universitário Norte do Espírito Santo, Universidade Federal do \\ Espírito Santo. \\ 1* debora.p.araujo@ufes.br ${ }^{2}$ emanuel2017.henrique@gmail.com
}

\section{ARTIGO INFO.}

\section{Recebido em: 29.06.2021}

Aprovado em: 18.08.2021

Disponibilizado em: 14.10.2021

\section{Palavras-chave:}

Curcumina; inibidor de urease; ancoragem molecular.

KEYWORDS:

Curcumin; urease inhibitor; docking molecular.

*Autor Correspondente: Araujo, D. P.

\section{RESUMO}

As ureases são enzimas que catalisam a hidrólise da ureia, formando amônia, gás carbônico e água. A hidrólise da ureia desempenha um papel importante no ciclo do nitrogênio, pois fornece esse elemento para o crescimento de microrganismos e plantas. Entretanto, a ação excessiva da urease leva à vários problemas em organismos vivos e, também, pode causar danos ambientais e econômicos. Os inibidores de urease podem ser uma boa alternativa para o tratamento de doenças causadas por microrganismos patogênicos dependentes da enzima urease. A curcumina, um produto natural obtido da Curcuma longa, é conhecida no Brasil como açafrão, e possui uma estrutura com capacidade de complexar metais, tornando-a um potencial inibidor de metaloproteínas, como a urease. Por esse motivo, nesse trabalho foi avaliado o potencial de interação da curcumina e de onze análogos com o sítio ativo da enzima urease utilizando os programas Autodock e Mopac2016. Os resultados mostraram que nove compostos possuem maior interação com o sítio ativo da enzima urease quando comparados com o substrato ureia, apresentando energias de ligação entre -7,24 e $-5,12$ $\mathrm{kcal} / \mathrm{mol}$, enquanto a ureia apresentou energia de ligação igual a $-4,10 \mathrm{kcal} / \mathrm{mol}$. O produto natural curcumina ficou na quinta posição, apresentando energia de ligação de $-6,21 \mathrm{kcal} / \mathrm{mol}$, demonstrando grande potencial para o uso como inibidor da enzima urease.

\begin{abstract}
Ureases are enzymes that catalyze the hydrolysis of urea into carbon dioxide, ammonia and water. The hydrolysis of urea plays an important role on nitrogen cycle, once it provides such element for the growth of microorganisms and plants. However, the excessive action of the urease leads to several problems in living microorganisms, and it can cause economic and environmental damages as well. Urease inhibitors can be a good alternative for the treatment of diseases caused by pathogenic microorganisms, which are dependents on the urease enzyme. The Curcumin, a natural product from the curcuma longa, known in Brazil as saffron, has a structure capable of complexing metals, which makes it a potential inhibitor of metalloproteins just like the urease. For such reason, this work aimed to evaluate the potential of interaction of the curcumin and eleven analogues with the active site of the urease enzyme, using the Autodock and Mopac2016 programs for that. Based on the results, it was observed that nine compounds showed a better interaction with the active site of the urease enzyme when compared to the urea substrate, presenting then binding energies between -7,24 and -5,12 $\mathrm{kcal} / \mathrm{mol}$, while the urea presented such energy equals to $-4,10 \mathrm{kcal} / \mathrm{mol}$. The curcumin got the fifth position by presenting a binding energy equals to $6,21 \mathrm{kcal} / \mathrm{mol}$, demonstrating a greater potential for being used as urease enzyme inhibitor.
\end{abstract}




\section{INTRODUÇÃO}

A urease é uma metaloenzima, que atua na hidrólise da ureia, formando amônia e dióxido de carbono (Figura 1), sendo produzida por plantas, fungos e bactérias (Khan et al., 2010). Ureases de fungos e plantas são proteínas homo-hexaméricas com subunidades de $90 \mathrm{kDa}$, enquanto as ureases bacterianas são multímeros de duas ou três subunidades complexas (Balasubramanian \& Ponnuraj, 2010). Apesar dessas diferenças, as ureases de plantas, de bactérias e de fungos possuem estruturas monoméricas semelhantes, inclusive o sítio ativo (Balasubramanian \& Ponnuraj, 2010).

Figura 1. Reação de hidrólise enzimática da ureia.



Fonte: Autores

A reação de hidrólise promovida pela urease ocorre no sítio ativo contendo um centro binuclear de Ni ligado em ponte por um resíduo de lisina carbamilada e por um íon hidróxido (Figura 2). Cada íon metálico está ligado à resíduos de histidina e à uma molécula de água, além do Ni2 estar ligado também à um resíduo de aspartato, completando-se suas esferas de coordenação. O Ni1 apresenta um arranjo de pirâmide quadrática distorcida, enquanto o Ni2 apresenta-se organizado como um pseudo-octaedro (Barrios \& Lippard, 2000).

Figura 2. Sítio ativo da enzima urease da bactéria Klebsiella aerogenes (Barrios \& Lippard,

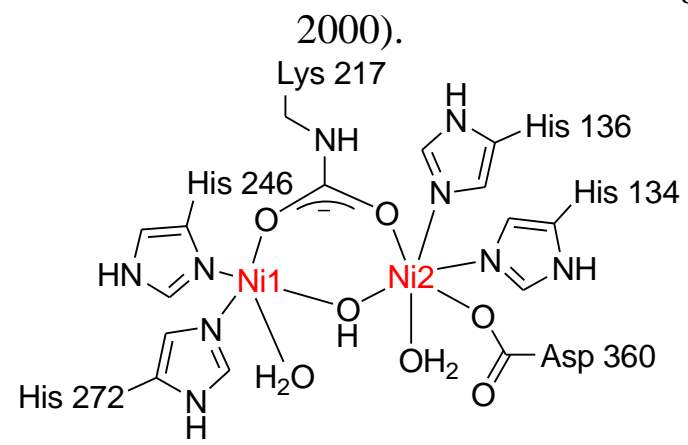

Fonte: Autores

A hidrólise da ureia desempenha um papel importante no ciclo do nitrogênio, pois fornece esse elemento para o crescimento de microrganismos e plantas (Ali et al., no prelo). Entretanto, a ação excessiva da urease leva à vários problemas em organismos vivos e, também, pode causar danos ambientais e econômicos (Ali et al., no prelo; Arshad et al., 2017). A hidrólise excessiva da ureia durante a fertilização na agricultura, aumenta a concentração de amônia no ar e no solo, causando sérios problemas ambientais (Ali et al., no prelo; Arshad et al., 2017). Em humanos e em outros animais, a hiperatividade da urease leva à vários problemas patológicos, tal como pedra nos rins, úlceras pépticas, artrite, pielonefrite, encefalopatia hepática, coma hepático, entre outras (Ali et al., no prelo; Elbastawesy et al., no prelo).

A enzima urease é indispensável para a colonização da mucosa gástrica humana por Helicobacter pylori (Ali et al., no prelo). A amônia formada durante a hidrólise enzimática 

Brazilian Journal of Production Engineering, 7(5), 17-29.

atua como receptor de prótons liberados pelas células parietais presentes nas glândulas gástricas, tornando o $\mathrm{pH}$ do interior da bactéria neutro, conferindo à $H$. pylori resistência a acidez gástrica, e formando um ambiente adequado para o seu crescimento, levando à úlceras e à cânceres gástricos (Ladeira, Salvadori, Rodrigues, 2003; Modolo, De Souza, Horta, Araujo, De Fátima, 2015; Elbastawesy et al., no prelo). Em vista disso, os inibidores de urease podem ser uma boa alternativa para o tratamento de doenças causadas por microrganismos patogênicos dependentes da enzima urease (Mamidala, Bhimathati, Vema, 2021). Entretanto, os inibidores de urease disponíveis comercialmente, como os fosforodiamidatos, derivados do ácido hidroxâmico e imidazóis, são tóxicos e de baixa estabilidade, características que impedem o seu uso clínico (Modolo et al., 2015).

Nos últimos anos, a terapia recomendada para a erradicação da $H$. pylori consistiu na combinação dos antibióticos amoxicilina e claritromicina junto com o omeprazol, um inibidor celular da bomba de prótons (Modolo et al., 2015). Contudo, o aumento da resistência da $H$. pylori por esses antibióticos tornou essas terapias ineficientes. Outros tratamentos vêm sendo utilizados com sais de bismuto, combinados com um inibidor celular de bomba de prótons ou com outras classes de antibióticos como, por exemplo, fluoroquinolonas, aminopenicilinas, tetraciclinas, etc (Modolo et al., 2015).

Estudos realizados por Ahmed e colaboradores (2017) com a curcumina (CUR) e 23 derivados demonstraram potenciais para inibir a enzima urease in vitro e por ancoragem molecular. Entre os compostos testados, o mais promissor foi o composto 8b (Figura 3), apresentando uma concentração necessária para inibir $50 \%$ da atividade da enzima $\left(\mathrm{CI}_{50}\right)$ igual a 2,44 $\pm 0,07 \mu \mathrm{M}$, sendo mais potente do que o inibidor referência tioureia $\left(\mathrm{CI}_{50}=\right.$ 22,61 $\pm 0,23 \mu \mathrm{M}$ ) (Ahmed et al., 2017).

Figura 3. Estrutura química do derivado da CUR 8b (Ahmed et al., 2017).<smiles>COc1cc(/C=C/c2cc(/C=C/c3ccc(O)c(OC)c3)[nH]c(=S)n2)ccc1O</smiles>

Fonte: Autores

A CUR e seus derivados naturais, chamados de curcuminoides (Figura 4), são compostos naturais presentes em um arbusto comum na Índia chamado de Curcuma longa (Ruby, Kuttan, Babu, Rajasekharan, Kuttan, 1995; Sueth-Santiago, Mendes-Silva, Decoté-Ricardo, De Lima, 2015). Ela é obtida da desidratação e moagem do rizoma da planta, gerando um pó amarelo, amplamente usado como tempero na culinária indiana. Este pó amarelo é conhecido no Brasil pelo nome de açafrão (Wanninger, Lorenz, Subhan, Edelmann, 2015; SuethSantiago, Mendes-Silva, Decoté-Ricardo, De Lima, 2015). Esses compostos apresentam em sua estrutura uma $\beta$-dicetona com alta propensão em complexar metais (Wanninger et al., 2015), que pode se ligar aos íons níquel do sítio ativo da enzima urease e competir com o 
substrato ureia. Dessa forma, o açafrão, um produto natural e não tóxico, apresenta elevado potencial para inibir a atividade da enzima urease.

Figura 4. Estrutura química dos principais curcuminoides encontrados na Curcuma longa: a curcumina, a desmetoxicurmina e a bisdesmetoxicurcumina.<smiles>[R]c1cc(/C=C/C(=O)CC(=O)/C=C/c2ccc(O)c(Br)c2)ccc1O</smiles>

Curcumina $\left(\mathrm{R}_{1}=\mathrm{OCH}_{3}\right.$ e $\left.\mathrm{R}_{2}=\mathrm{OCH}_{3}\right)$ Desmetoxicurcumina $\left(\mathrm{R}_{1}=\mathrm{OCH}_{3}\right.$ e $\left.\mathrm{R}_{2}=\mathrm{H}\right)$

Bisdesmetoxicurcumina $\left(\mathrm{R}_{1}=\mathrm{H}\right.$ e $\left.\mathrm{R}_{2}=\mathrm{H}\right)$

Fonte: Autores

Atualmente, vários grupos de pesquisa estão investindo no estudo da ancoragem molecular para investigar a interação entre uma molécula bioativa e seu sítio ativo, avaliando as características estruturais e as propriedades físico-químicas, visando um planejamento mais racional de novos compostos (Ali et al., no prelo; Elbastawesy et al., no prelo). As estruturas tridimensionais de uma molécula bioativa podem ser manipuladas na tela do computador e sobrepostas em seu possível sítio alvo. Esse tipo de processo permite investigar o potencial de ligação, para que haja o acoplamento eficiente entre a molécula bioativa e seu sítio-alvo (Thomas, 2003). Alguns programas computacionais vêm sendo desenvolvidos para permitir a visualização das conformações tridimensionais tanto dos ligantes como de seus sítios-alvo (Thomas, 2003). Isto permite uma síntese mais racional, possibilitando ao pesquisador sintetizar somente os compostos mais promissores, reduzindo o custo, o tempo do desenvolvimento e o impacto ambiental com o desperdício de reagentes químicos e solventes.

$\mathrm{Na}$ busca por inibidores de urease eficientes e não tóxicos, o objetivo desse trabalho foi realizar a ancoragem molecular da CUR e de onze análogos no sítio ativo da enzima urease, avaliando as energias livres de ligação e suas interações com os resíduos de aminoácidos.

\section{Metodologia}

Para a realização da ancoragem molecular da curcumina e de seus análogos com o sítio ativo da enzima urease, utilizou-se os programas Autodock e Mopac2016 (Biazus, 2015). Os programas Discovery Studio e Pymol foram utilizados para o estudo de interações com os resíduos de aminoácidos (Da Silva, 2017). Os arquivos das estruturas 3D dos ligantes foram retirados da base de dados PubChem e o arquivo da proteína foi retirado da base Protein Data Bank, registrada pelo código $3 \mathrm{La} 4$.

O programa Autodock faz uso do Algoritmo Genético Lamarckiano (AGL) para a realização da ancoragem molecular, utilizando-se as diferentes conformações dos ligantes, explorando suas torções e energias de ligação. O programa realiza múltiplas simulações, onde o ligante é disposto de forma aleatória no espaço e ancorado com o receptor, seguido pelo cálculo da energia livre de ligação em kcal/mol do complexo ligante-receptor (Da Silva, 2017). Dessa forma, são selecionadas as melhores conformações para a utilização do Algoritmo Genético e, a partir daí, realizam-se ciclos de geração até um máximo de gerações. Esses dados são baseados na teoria de Lamarck da hereditariedade de mutações ou mudanças adquiridas pela geração anterior, levando em consideração fatores de permutação como: crossing-over (possuindo o mesmo nome do fenômeno genético, onde ocorre a troca de material gênico 
entre cromossomos) e mutação (são modificações aleatórias da posição de alelos gênicos). Ambos os processos promovem a variabilidade genética e garantem que durante a ancoragem molecular não haja a prevalência de uma conformação ou elitismo (Da Silva, 2017). Os seguintes parâmetros foram definidos para a ancoragem molecular: tamanho da população igual a 150; o número máximo de avaliações igual a 2.500.000; o número máximo de gerações 27.000; a taxa de mutação igual a 0,02; e a taxa de crossing-over igual a 0,8.

Quando é executado o programa é empregado o AGL, explorando as torções do ligante e buscando as melhores conformações. Cada simulação gera uma população de indivíduos, onde é calculado a energia livre de ligação do complexo ligante-receptor (G) somando-se as energias de Van der Waals (Gvdw), das Ligações de Hidrogênio (Ghbond), do Potencial Eletrostático $\left(\mathrm{G}_{\text {ele }}\right)$, das Torções $\left(\mathrm{G}_{\mathrm{conf}}\right)$ e da Solvatação $\left(\mathrm{G}_{\text {solv }}\right)$, representadas na Equação 1 (Da Silva, 2017).

Equação 1. $G=G_{v d w}+G_{h b o n d}+G_{e l e}+G_{c o n f}+G_{s o l v}$

\section{RESUlTADOS E DISCUSSÃO}

Para a realização da ancoragem molecular, treze compostos foram avaliados: o substrato ureia, a CUR e seus onze análogos (1-11), que possuem variação do grupo substituinte no anel aromático (Tabela 1).

Tabela 1. Energias de ligação e resíduos de aminoácidos envolvidos na interação dos compostos ureia, CUR e os análogos de $\mathbf{1}$ a $\mathbf{1 1}$ com o sítio ativo da enzima urease.

Compostos


6<smiles>O=C(/C=C/c1ccccc1)CC(=O)/C=C/c1ccccc1</smiles><smiles>O=C(/C=C/c1cccc([N+](=O)[O-])c1)C/C=C/c1cccc([N+](=O)[O-])c1</smiles>

8<smiles>CN(C)c1ccc(/C=C/C(=O)CC(=O)/C=C/c2ccc(N(C)C)cc2)cc1</smiles>

9<smiles>O=C(/C=C/c1ccc(S)cc1)CC(=O)/C=C/c1ccc(S)cc1</smiles>

$-6,04$

$-5,16$

$-5,12$
Tyr814(a), Pro555(a) Asp556(a), His553(a), Asn524(a), Lys559(A), Ala554(a), Phe605(a), Ser608(a), Thr522(a) Asp556(a), Pro811(a), Phe528(a), Pro555(a), Ala554(a), Asn524(a), Tyr814(a)

Phe605(a), Thr522(a), Pro555(a), Val539(a), Glu530(a), Asp556(a), Phe528(a), Asn524(a), Tyr814(a), Ala524(A), Leu523(a), Phe605(a), Thr522(a)

Phe605(a), Ala554(a), Ser608(a), Tyr814(a), Pro555(a), Pro811(a), Asp556(a), Phe528(a), Glu530(a), Leu523(a)

Tyr554(a), Gly551(a), His(a), Thr520(a), Gly552(a), Ile5118(a)

Ala604(a), Tyr814(a), Pro811(a), Pro555(a), Ala554(a), Phe528(a)

Tyr608(a), Ile677(a), Phe713(a), Trp648(a), Ala403(a), Thr400(a), Ile644(a), Lys716(a)

Os volumes moleculares dos compostos foram avaliados pelo programa Mopac2016 (Tabela 2), com o propósito de mensurar as moléculas que apresentam menor impedimento estérico e, consequentemente, maior potencial de acessar o interior da cavidade do sítio catalítico da enzima.

Tabela 2. Volumes moleculares dos compostos avaliados.

\begin{tabular}{cc}
\hline Compostos & Volumes (Ångström cúbico) \\
\hline $\mathbf{1}$ & 372,77 \\
$\mathbf{2}$ & 374,25 \\
$\mathbf{3}$ & 372,65 \\
$\mathbf{4}$ & 415,55 \\
\hline CUR & 433,25 \\
$\mathbf{5}$ & 385,55 \\
$\mathbf{6}$ & 296,24 \\
$\mathbf{7}$ & 417,98 \\
$\mathbf{8}$ & 468,38 \\
$\mathbf{9}$ & 458,44 \\
\hline Ureia & 71,53 \\
$\mathbf{1 0}$ & 549,86 \\
$\mathbf{1 1}$ & 506,44 \\
\hline
\end{tabular}


Os compostos mais promissores na inibição da enzima urease foram aqueles que apresentaram menor energia de ligação (Tabela 1) em conjunto com um menor volume molecular (Tabela 2), além de interações fortes, como ligações de hidrogênio, ligações de halogênio, e ânion- $\pi$, com os resíduos de aminoácidos do sítio ativo da enzima ou próximo à ele (Fokoue et al., 2020). As interações alquila-arila são interações do tipo dipolo-dipolo induzido fracas, mas podem ter um papel significativo nas conformações e na estabilidade da estrutura do complexo ligante-proteína (Fokoue et al., 2020). Baseado nesses parâmetros, o composto que demonstrou maior interação com a enzima urease foi o análogo 1 (Tabela 1), por realizar quatro ligações de hidrogênio, três com os grupos hidroxila na posição meta do anel aromático e uma com a carbonila da $\beta$-dicetona (Figura 5). Um anel aromático formou interações ânion- $\pi$ com o resíduo ASP556, um aminoácido importante para a ancoragem do ligante no sítio ativo da enzima (Figura 5). Além do grupo hidroxila desse mesmo anel aromático realizar uma ligação de hidrogênio com o resíduo VAL529, reduzindo a distância de ligação com a enzima (Figura 6).

Figura 5. Representação das estruturas $2 \mathrm{D}$ dos três análogos da CUR mais promissores (compostos 1, 2 e 3), e os respectivos resíduos de aminoácidos do sítio catalítico da enzima urease que cada um interage.

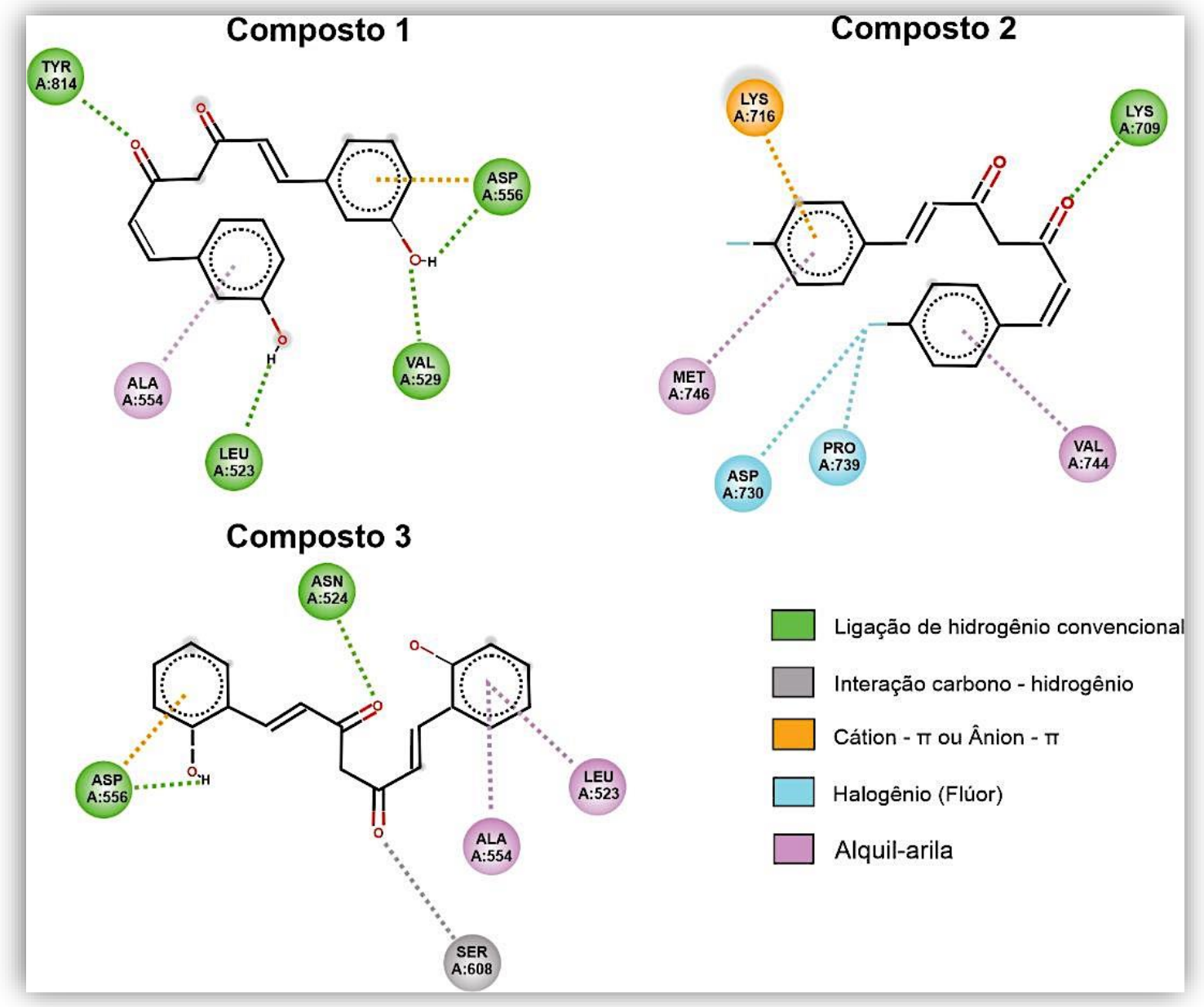

Fonte: Figura adaptada do programa Discovery Studio 
Os análogos 2 e 3 apresentaram energias de ligação e volumes muito semelhantes (Tabela 1 e 2). O análogo 2 realizou duas ligações fortes de halogênio do substituinte fluoro de um anel aromático com os resíduos ASP730 e PRO739, além de uma interação ânion- $\pi$ do outro anel aromático com a LYS716, e uma ligação de hidrogênio de uma carbonila da $\beta$-dicetona com a LYS709 (Figura 5). Já o análogo 3, fez duas ligações de hidrogênio e uma interação do tipo ânion- $\pi$ com o ASP556 (Figura 5). Apesar de possuir um grupo hidroxila em orto no anel aromático, o análogo $3 \mathrm{fez}$ menos ligações de hidrogênio do que o $\mathbf{1}$, apresentando maior distância de ligação com a enzima (Figura 6).

Figura 6. Representação da estrutura 3D dos análogos 1 e $\mathbf{3}$ que estabelecem interações ânion- $\pi$ e/ou ligações de hidrogênio com o resíduo de aminoácido ASP556, um aminoácido importante para o acoplamento do ligante no sítio ativo da enzima.

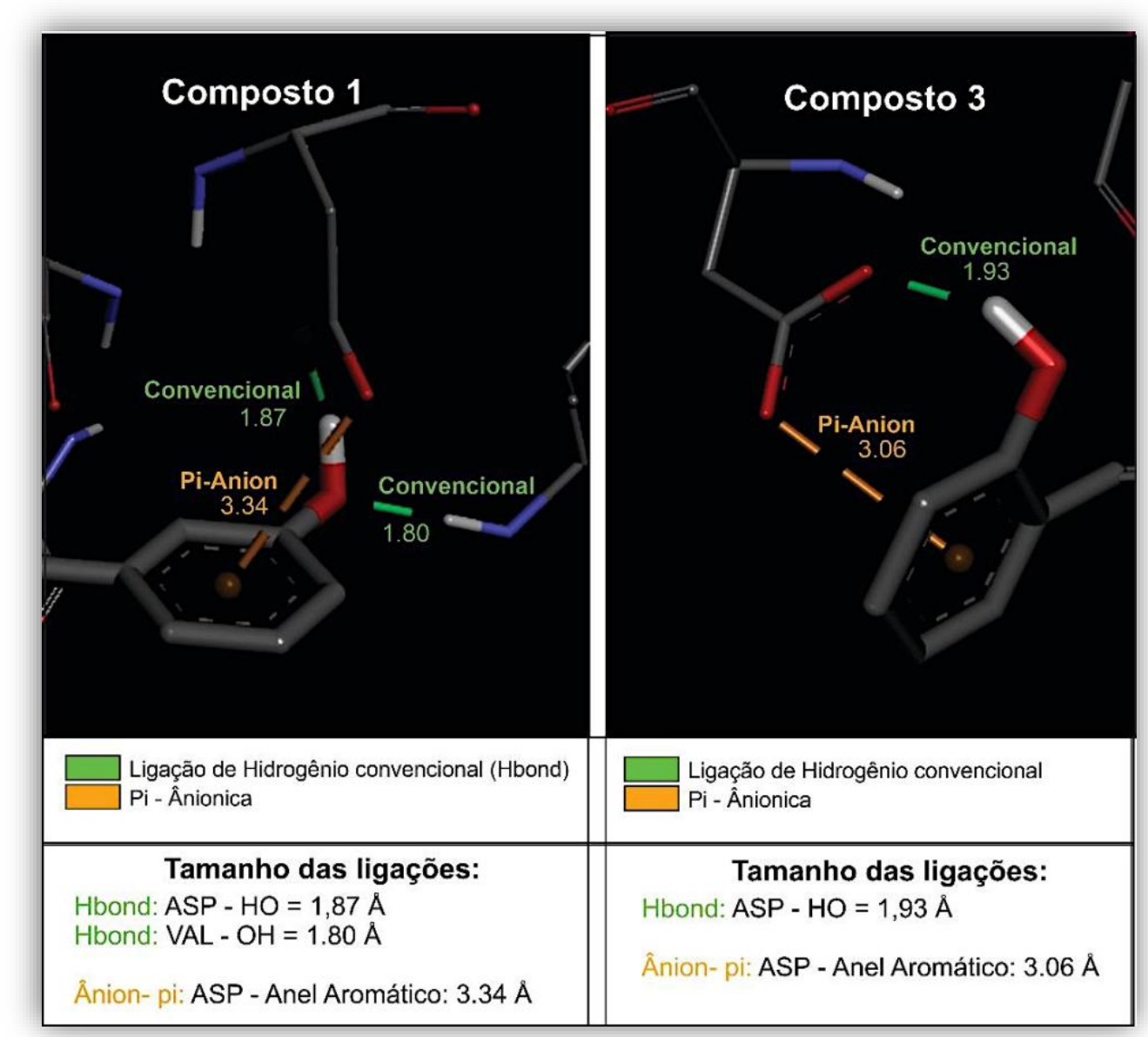

Fonte: Figura adaptada do programa Discovery Studio

O composto 4 exibiu menor interação com a enzima do que os análogos $\mathbf{1}$ a $\mathbf{3}$ (Tabela 1), devido a presença de um grupo metoxila no anel aromático, o que resulta em um volume maior da molécula e, consequentemente, aumenta o impedimento estérico (Tabela 2). Entretanto, o composto 4 fez duas ligações de hidrogênio e duas ligações do tipo ânion- $\pi$ com o ASP556 e a LYS559 (Figura 7), demonstrando forte interação com os resíduos de aminoácidos da enzima.

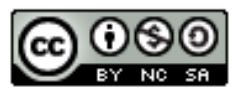


Figura 7. Representação da estrutura 2D do composto 4 e da sua interação com os respectivos resíduos de aminoácidos do sítio catalítico da enzima urease.

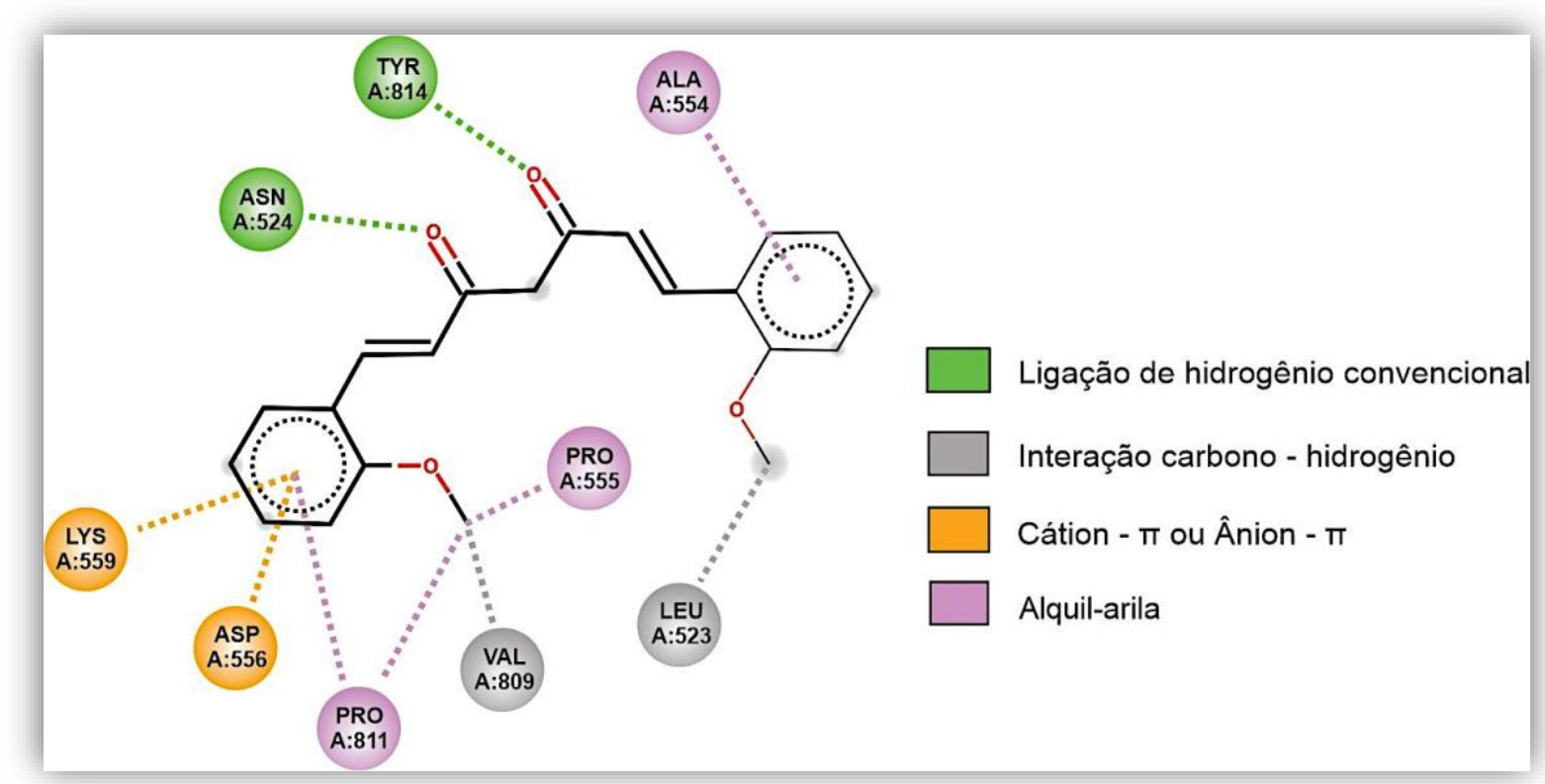

Fonte: Figura adaptada do programa Discovery Studio

A CUR possui dois grupos substituintes no anel aromático, um grupo metoxila e um grupo hidroxila nas posições meta e para, respectivamente. Logo, ela apresentou um volume molecular maior do que os análogos com apenas um ou nenhum grupo substituinte (Tabela 2). Porém, o que tornou a CUR um inibidor da enzima urease mais eficiente do que os compostos 5, $\mathbf{6}$ e $\mathbf{7}$ que apresentaram menores volumes, foram as fortes interações com o sítio ativo da enzima, apesar do seu maior impedimento estérico (Figura 8). Observou-se uma ligação do tipo ânion- $\pi$ com o resíduo ASP556, quatro ligações de hidrogênio com os resíduos VAL809, LYS559, ASN524 e TYR814, além de outras interações mais fracas (Figura 8), estabelecendo-se assim um forte acoplamento com a enzima.

Figura 8. Representação da estrutura 2D da CUR e da sua interação com os respectivos resíduos de aminoácidos do sítio ativo da enzima urease.

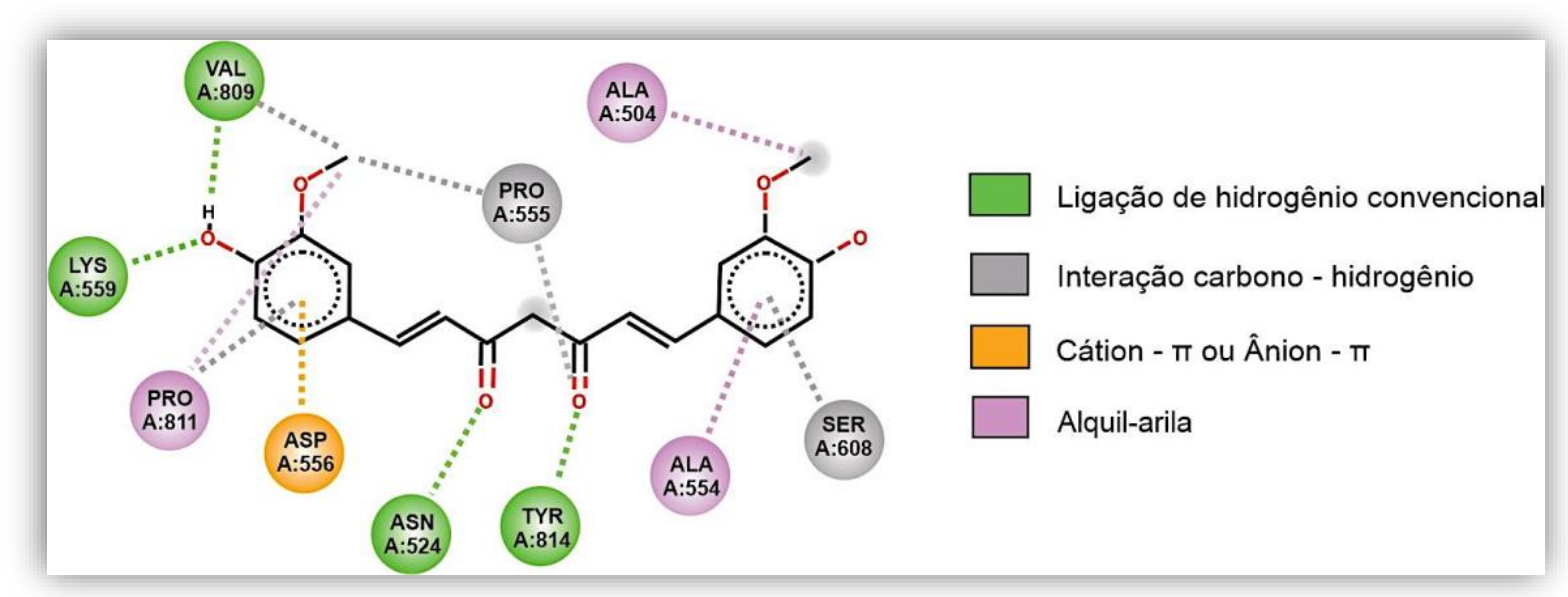

Fonte: Figura adaptada do programa Discovery Studio

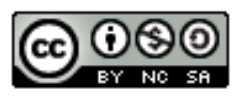


Os compostos 5 e 6, apesar de serem menos volumosos do que a CUR (Tabela 2), não realizaram interações tão fortes quanto ela (Tabela 1). $\mathrm{O}$ análogo 5 possui um grupo substituinte cíclico, tornando essa estrutura mais rígida e diminuindo o seu grau de liberdade (Figura 9). O análogo 6, por não conter grupos substituintes, não realizou interações fortes com os anéis aromáticos. Há previsão somente de uma interação do tipo ânion- $\pi$ com o resíduo ASP556, e uma ligação de hidrogênio de uma carbonila da $\beta$-dicetona com a TYR814 (Figura 9).

Figura 9. Representação da estrutura 2D de interação dos compostos 5 e $\mathbf{6}$ com seus respectivos resíduos de aminoácidos do sítio ativo da enzima urease.

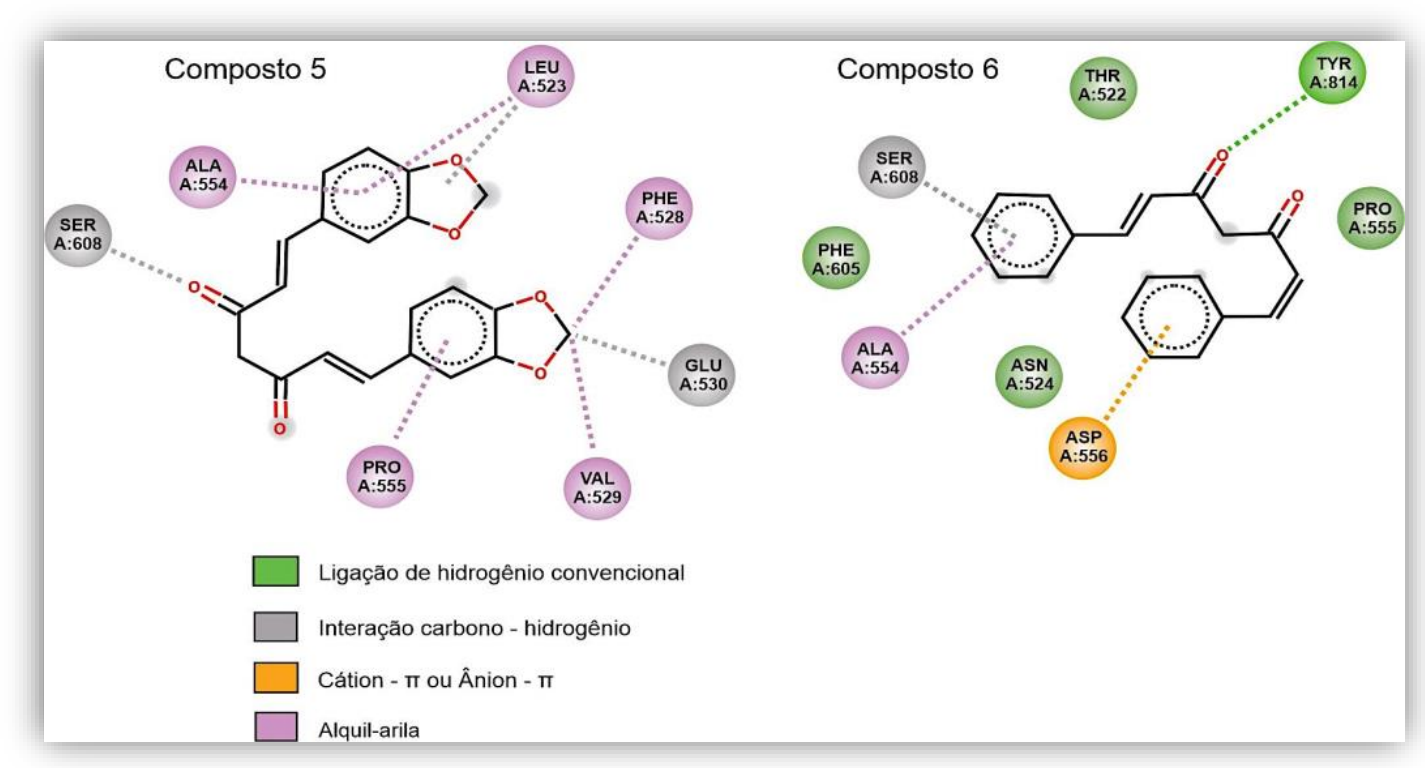

Fonte: Figura adaptada do programa Discovery Studio

O análogo 7 da CUR, apesar de apresentar fortes interações, como ligações de hidrogênio e ânion- $\pi$ com o resíduo ASP556 (Figura 10), obteve uma menor interação total com a enzima, quando comparado com os compostos anteriores por ser uma molécula mais volumosa (Tabela 2).

Figura 10. Representação da estrutura 2D do composto 7 e de sua interação com os respectivos resíduos de aminoácidos do sítio ativo da enzima urease.

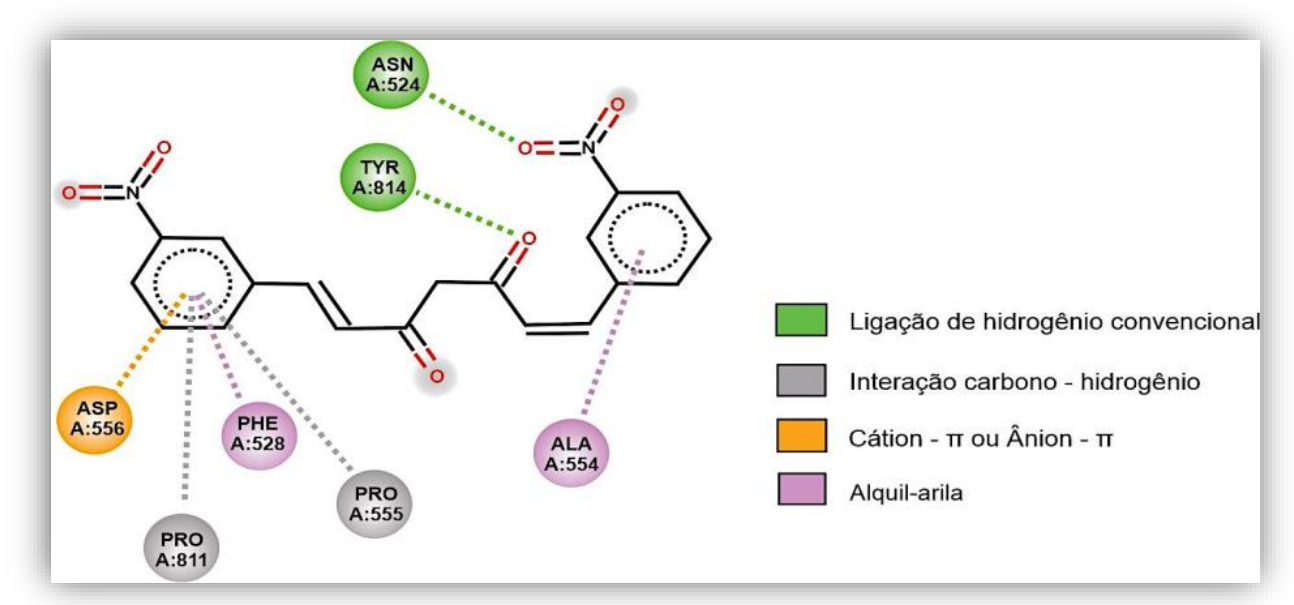

Fonte: Figura adaptada do programa Discovery Studio 
Os compostos 8 e 9 demonstraram resultados semelhantes entre si, tanto de interação com a enzima urease, quanto de volume molecular (Tabelas 1 e 2), e apresentaram maior interação com o sítio ativo da urease do que o substrato ureia.

Figura 11. Representação da estrutura 2D dos compostos $\mathbf{8}$ e 9, e de suas interações com os respectivos resíduos de aminoácidos do sítio ativo da enzima urease.

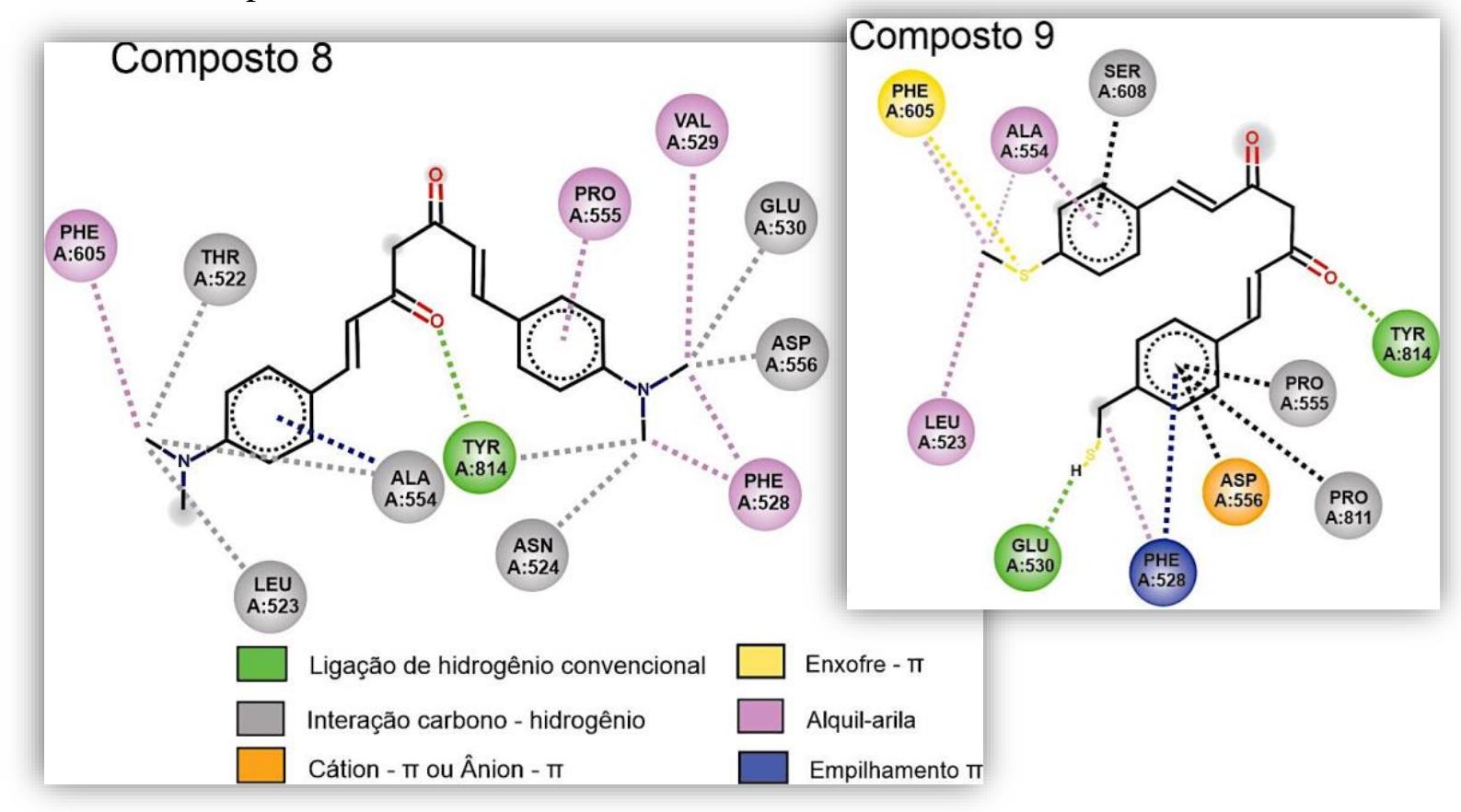

Fonte: Figura adaptada do programa Discovery Studio

Os análogos 10 e 11 apresentaram menor interação com a urease do que o substrato ureia (Tabela 1). Logo, não são promissores para a utilização como inibidores da enzima urease. Os três grupos substituintes do anel aromático, tornaram as moléculas muito volumosas (Tabela 2), gerando vários impedimentos estéricos (Figura 12). As interações do composto 11 com o sítio ativo da enzima foram as mais desfavorecidas, apesar de ele possuir uma hidroxila em para e ser menos volumoso do que o 10, que possui uma metoxila na mesma posição (Figura 12). O análogo 11 demonstrou várias interações desfavoráveis com a enzima, não conseguindo estabelecer uma conexão com o sítio ativo da enzima. 
Figura 12. Representação da estrutura 2D dos compostos 10 e 11, e de suas interações com os respectivos resíduos de aminoácidos do sítio ativo da enzima urease.

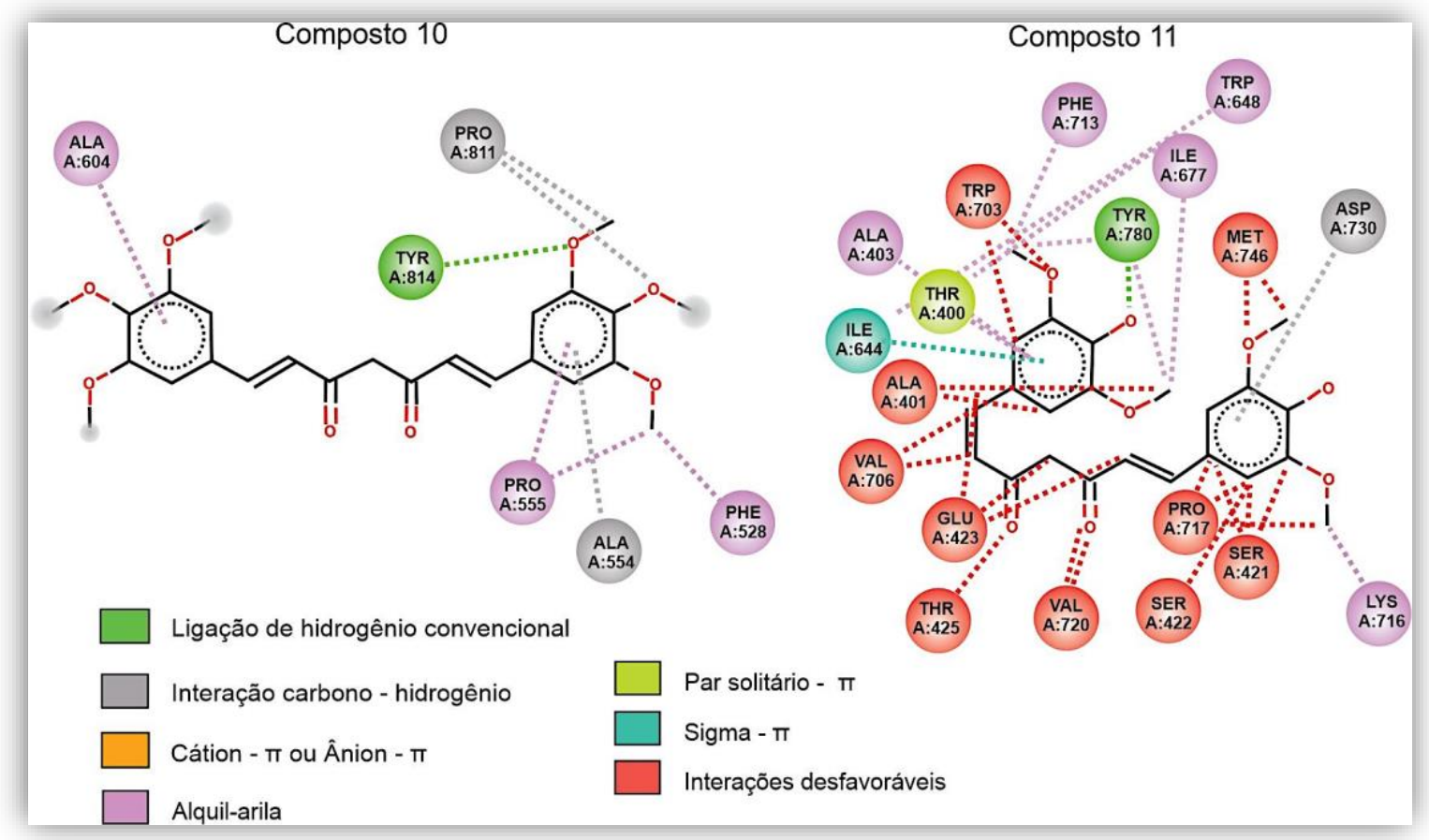

\section{Conclusão}

Fonte: Figura adaptada do Discovery Studio

Entre os doze compostos avaliados, nove deles e a CUR apresentaram interação mais efetiva com o sítio ativo da enzima quando comparados com o substrato ureia, apresentando energias de ligação entre -7,24 e -5,12 kcal/mol, enquanto a ureia apresentou energia de ligação igual a $-4,10 \mathrm{kcal} / \mathrm{mol}$. Esses compostos podem ser candidatos para o uso no tratamento de doenças causadas por microrganismos patogênicos dependentes da enzima urease, como a $\mathrm{H}$. pylori. Entretanto, ainda é necessário realizar os testes de inibição da enzima urease in vitro, para confirmar a previsão teórica obtida por ancoragem molecular.

\section{Agradecimentos}

Agradecemos à Fundação de Amparo à Pesquisa e Inovação do Espírito Santo (FAPES) e ao Conselho Nacional de Desenvolvimento Científico e Tecnológico (CNPq) pelo financiamento do projeto "Docking molecular, avaliação in vitro e no solo de potenciais inibidores de urease derivados da curcumina" do Edital No 04/2017-Programa Primeiros Projetos, tornando este trabalho possível. Também expressamos nossos sinceros agradecimentos à instituição de vínculo da equipe executora, a Universidade Federal do Espírito Santo (UFES).

\section{REFERÊNCIAS BIBLIOGRÁFICAS}

Ahmed, M., Qadir, M. A., Hameed, A., Arshad, M. N., Asiri, A. M., \& Muddassar, M. (2017). Azomethine, isoxazole, N-substituted pyrazoles and pyrimidine containing curcumin derivatives: Urease inhibition and molecular modeling studies. Biochemical and Biophysical Research Communications, 490, 434-440.

Ali, F., Shamim, S., Lateef, M., Khan, K. M., Taha, M., Salar, U., Wadood, A., Rehman, A. U., Nawaz, N. U. A., \& Perveen, S. (2021). N-Aryl-3,4-dihydroisoquinoline carbothioamide analogues as potential urease inhibitors. ACS Omega, no prelo.

Arshad, T., Khan, K. M., Rasool, N., Salar, U., Hussain, S., Asghar, H., Ashraf, M., Wadood, A., Riaz, M., Perveen, S., Taha, M., \& Ismail, N. H. (2017). 5-Bromo-2-aryl benzimidazole 

Brazilian Journal of Production Engineering, 7(5), 17-29.

derivatives as non-cytotoxic potential dual inhibitors of a-glucosidase and urease enzymes. Bioorganic Chemistry, 72, 21-31.

Balasubramanian, A., \& Ponnuraj, K. (2010). Crystal Structure of the First Plant Urease from Jack Bean: 83 Years of Journey from Its First Crystal to Molecular Structure. Journal of Molecular Biology, 400(3), 274-283.

Barrios, A. M., \& LIPPARD, S. J. (2000). Interaction of Urea with a Hydroxide-Bridged Dinuclear Nickel Center: An Alternative Model for the Mechanism of Urease. Journal of the American Chemical Society, 122(38), 9172-9177.

Biazus, M. (2015). Modelagem e Análise de Conformidade do Processo Presente em Estratégias Computacionais de Atracamento Molecular (Trabalho de conclusão de curso de graduação). Instituto de Informática da Universidade Federal do Rio Grande do Sul, Porto Alegre, Rio Grande do Sul.

Silva, V. A., da (2017). Estudo, por modelagem molecular, da inibição da enzima acetohidroxiácido sintase utilizando diferentes derivados pirimidinilsalicilatos (Dissertação de mestrado). Universidade Federal de Uberlândia, Uberlândia, Minas Gerais.

Elbastawesy, M. A. I, Aly, A. A., El-Shaier, Y. A. M. M., Brown, A. B., Abuo-Rahma, G. E. A., \& Ramadan, M. (2021). New 4-thiazolidinone/quinoline-2-ones scaffold: Design, synthesis, docking studies and biological evaluation as potential urease inhibitors. Journal of Molecular Structure, no prelo.

Fokoue, H. H., Pinheiro, P. S. M., Fraga, C. A. M., \& Sant'Anna, C. M. R. (2020). Há algo novo no reconhecimento molecular aplicado à Química Medicinal?Química Nova,43(1),78-89 Khan, K. M., Wadood, A., Aali, M., Zia, U., Ul-haq, Z., Lodhi, M. A., Khan, M., Perveen, S., \& Choudhary, M. I. (2010). Identification of potent urease inhibitors via ligand- and structure-based virtual screening and in vitro assays. Journal of Molecular Graphics and Modelling, 28(8), 792-798.

Ladeira, M. S. P., Salvadori, D. M. F., \& Rodrigues, M. A. M. (2003). Biopatologia do Helicobacter pylori. Jornal Brasileiro de Patologia e Medicina Laboratorial, 39(4), 335-342. Mamidala, R., Bhimathati, S. R. S., \& Vema, A. (2021). Discovery of novel Dihydropyrimidine and hydroxamic acid hybrids as potent Helicobacter pylori urease inhibitors. Bioorganic Chemistry, 114, 105010.

Modolo, L. V., De Souza, A. X., Horta, L. P., Araujo, D. P., \& De Fátima, A. (2015). An overview on the potential of natural products as ureases inhibitors: A review. Journal of Advanced Research, 6(1), 35-44.

Stewart, J. J. P. (2016). MOPAC. (Versão 20.225W) [Software]. Colorado Springs, Colorado, EUA: Stewart Computation Chemistry. Recuperado de http://OpenMOPAC.net

PubChem, National Center of Biotechnology Information, 8600 Rockville Pike, Bethesda, MD, 20894 USA.

Ruby, A. J., Kuttan, G., Babu, K. D., Rajasekharan, K. N., \& Kuttan, R. (1995). Anti-tumour and antioxidant activity of natural curcuminoids. Cancer Letters, 94(1), 79-93.

Sueth-Santiago, V., Mendes-Silva, G. P., Decoté-Ricardo, D. \& De Lima, M. E. F. (2015). Curcumina, o pó dourado do açafrão-da-terra: introspecções sobre química e atividade biológicas. Química Nova, 38(4), 538-552.

Thomas, G. (2003). Química Medicinal: uma introdução (1 ${ }^{\mathrm{a}}$ ed).Rio de Janeiro: Guanabara Koogan.

Wanninger, S., Lorenz, V., Subhan, A., \& Edelmann, F. T. (2015) Metal complexes of curcumin-synthetic strategies, structures and medicinal applications. Royal Society of Chemistry Advances, 44(15), 4986-5002. 